\title{
The Demand for Rail Feeder Shuttles
}

\author{
David Anspacher, BMI-SG, Inc. \\ Asad J. Khattak, University of North Carolina at Chapel Hill \\ Youngbin Yim, University of California at Berkeley
}

\begin{abstract}
Rail transit systems offer opportunities for travelers to avoid traffic congestion in large urban areas. This article explores the possibility of expanding access to existing rail transit systems through demand responsive shuttles. It examines demand for such an innovation in the San Francisco Bay Area where relatively good rail service already exists. Using survey data collected in a case study of one urban and one suburban neighborhood ( $N=800$ individuals surveyed) served by the San Francisco Bay Area Rapid Transit agency, this article investigates the influence of several factors on people's willingness to use, pay for, and wait for the shuttles. The results indicate that a significant percentage of the surveyed population is willing to try the shuttle. Higher willingness to use the shuttle was associated with women, younger and elderly respondents, noncommuters who travel by SOV, and rail users who access the stations by transit. Higher willingness to pay for the shuttle was associated with suburbanites.
\end{abstract}

\section{Introduction}

Traditional transit systems in the United States evolved in response to the explosion of suburban development in the first half of the 20th century. They are characterized by transit routes that resemble radial spokes of a wheel, linking 
residential areas in the suburbs to commercial districts in the city. Since density in these suburbs tends to be low, residents have limited access to transit stations. Most live beyond the $1 / 4$ - to $1 / 2$-mile walking distance of the station. The minority of commuters who do not drive to their destinations often compete for scarce parkand-ride spaces, walk, or take transit to the station. In order to encourage more residents to ride transit, it has become necessary for transit agencies to expand the services they offer to make transit more accessible. One method that transit agencies utilize is feeder shuttle service. A rail feeder shuttle in the context of this study is an innovative and demand responsive system of vehicles and information/communication technologies that provide better access to express bus or rail transit. The system is intelligent and flexible. For instance, it collects commuters from their neighborhoods and brings them to transit stations or collects them at the station to return them to their neighborhoods.

The purpose of this study is twofold. First, it evaluates the potential market penetration of rail feeder shuttle service and investigates the extent to which shuttles can expand a transit agency's service area to travelers located outside of the station's vicinity. Second, it analyzes the factors that influence riders' willingness to use, pay for, and wait for shuttles. Using the San Francisco's Bay Area Rapid Transit (BART) system as a case study, this article reports results that can be valuable to other (similar) transit agencies.

\section{Literature Review}

A study of downtown San Francisco BART stations in the mid-1990s found that 2/3 of all access trips are by pedestrians (Cervero 1995), but as the distance between stations and the downtown increases, access to transit stations becomes increasingly limited to those with private vehicles. Automobiles account for 60 percent of access trips that are more than one mile from the nearest BART station (Cervero 1994). However, vehicle ownership does not guarantee access, due to limited parking availability. As a result, transit ridership often remains low, especially in suburban locations. For those communities that continue to opt for this type of development, the key to making transit effective is to adapt it to land-use realities. One way to increase ridership in suburban locations is to expand the service area of rail transit stations through innovative shuttle feeder systems.

Although demand responsive transit, sometimes known as dial-a-ride service, has long been a staple of paratransit systems serving the elderly and the disabled as 
mandated under the Americans with Disabilities Act (ADA), it is costly to implement. This is, in part, because of the need to staff a dispatch and order-taking center and, in part, because vehicles cannot be used to their highest efficiency (i.e., they make too many trips while they are empty, either to or from picking up riders). Operating cost per trip at Portland's Tri-Met is $\$ 1.99$ for rail and $\$ 2.39$ for bus, but more than $\$ 20.20$ for demand responsive service (FY 2002). For the Chicago Transit Authority, operating expense per trip for demand response is more than $\$ 24.00$ (FY 2002).

By combining smart components, such as automated dial-a-ride and scheduling and real-time vehicle location systems, vehicles can potentially carry more passengers in the same amount of time. They can also switch from operating on fixedroute schedules to flexible ones, which are more efficient during periods of low demand. With the help of new technologies, a rail feeder shuttle system could be suitable for low-demand areas and at low-demand times (i.e., off-peak hours). The system advantages also include personalization, curb-to-curb or door-to-door service, and user-orientation. Overall, such systems can improve access to line-haul, thereby increasing rail transit use more cost effectively than existing options, such as increasing parking or improving the fixed-route feeder bus system. However, a disadvantage is that such systems have not been tested and the dial-a-ride service in the context of ADA is costly.

In a survey of 40 APTS technology providers, Khattak and Hickman (1996) and Khattak, Noeimi, and Al-Deek (1998) found that innovations such as Automatic Vehicle Location (AVL) and Computer Aided Dispatch (CAD) can increase transit mode share by increasing the efficiency of transit vehicles, improving the level of service, and reducing costs. Users can benefit from reduced travel and wait times and increased security. Hickman and Blume (2001) found that by integrating shuttle service with fixed-route trips, Houston's METROLift could reduce operating costs by 15 percent and reduce travel time for 39 percent of its passengers. ADART (Autonomous Dial-a-Ride) is a completely automated system that gives trip scheduling, dispatching, and routing control to computers onboard the vehicles. The computers provide drivers with instructions to follow (Ghani and Dial 2004).

This study attempts to fill gaps in the literature by investigating willingness to use, pay for, and wait for transit feeder shuttles, assuming that innovations in rail feeder shuttles lead to costs, wait times, trip lengths, and scheduling times that are acceptable to the user. It also attempts to shed light on how transit agencies can 
potentially increase ridership and reduce operating subsidies by understanding demand and willingness to pay and wait for transit shuttles.

\section{Background}

The application of demand responsive rail feeder shuttles in the Bay Area grew out of concerns that riders were leaving BART for other, largely single-occupant, modes. Given that BART is a relatively high-quality rail system serving both urban and suburban locations, the reasons were largely related to access to BART. That is, people were leaving BART partly because of constrained access, insufficient parking at several BART stations, and poor transit service to and from the stations. In addition, land-use changes were limited in the short-term.

To assess demand for the innovative rail feeder shuttle, two Northern California locales, Glen Park and Castro Valley, were selected. Smart rail shuttles are being studied as a way to create new feeder systems that collect riders over a small geographic area and carry them to the existing transit system. In the case of Glen Park, shuttles will take riders to BART in Castro Valley and will feed riders to BART and Alameda County Transit express buses. In Castro Valley, testing the automated dial-up system on a bus route run by Alameda County (AC) Transit was particularly relevant, because the bus route was a candidate for elimination due to low ridership.

\section{Methodology}

To design the study, the Castro Valley and Glen Park neighborhoods in San Francisco were selected based on several criteria. The two study areas are similar in that they have a BART station but are relatively underserved in terms of access to the rail system, both have hilly neighborhoods with winding streets, are populated by middle- and upper-middle income households, and have similar total populations. A key difference is that Glen Park is located in an urban setting, while Castro Valley is located in a suburban setting. Homes in Glen Park are typically older row houses, while in Castro Valley they are newer and more spread out.

The locations were also selected based on sufficient variation in terms of physical city size, population density, distance from residences to existing BART stations, and racial mix. In addition, the parking supply was to be constrained at both BART stations. Additional (practical) considerations included BART interest in field testing a new shuttle service in an urban area and replacing an inefficient feeder bus 
service in the suburban area. The selection of these two cities made it possible to study the behavioral differences related to the shuttle service between urban and suburban neighborhoods.

\section{Study Design and Survey Description}

We followed a cross-sectional experimental research design by (randomly) surveying an urban and a suburban location around BART stations. The expectation was that suburban residents might be more inclined to respond positively to a rail feeder shuttle compared with urban residents. Since both communities were in the San Francisco Bay Area, we were able to control experimentally for differences in macro factors such as economy and some public services. Of course, the focus on two cities in a single area limits our ability to generalize from the current study. Nonetheless, these cities can be considered as prototypical of similar cities elsewhere in the United States, and more specifically on the west coast.

After selecting the two cities, a random digit dialing survey instrument was implemented using the CATI (computer aided telephone interview) technique. A professional firm was hired for this purpose. A sample size of 800 was considered reasonable based on statistical calculations and practical (mostly budget) considerations. To increase the response rate, the contracting firm made several repeat calls to nonresponders. Respondents were required to be at least 18 years old, ${ }^{1}$ with no more than 52 percent female and 48 percent male (the Bay Area male and female ratio).

The survey contained several hypothetical questions that asked about willingness to use, pay for, and wait for a rail feeder shuttle. The socioeconomic and travel context questions were asked in a manner typical in travel behavior surveys, which are considered fairly reliable. The hypothetical questions about willingness to use and pay for the service are based on contingent valuation studies. The question about willingness to use begins by asking:

Now l'd like to talk about a shuttle service that is being considered for your neighborhood to provide easy access to BART. Suppose a shuttle service was available that provided round-trip transportation to the closest BART station from a pick-up location near your home. The service would use comfortable, air-conditioned vans and pick-ups would be scheduled for convenient times throughout the day and would be coordinated with BART train schedules. Please tell me how interested you are in this type of shuttle ser- 
vice, without considering the cost, using a one-to-five scale where one means you are "not at all interested" and five means you are "very interested."

The question about payment reads:

Suppose the per passenger cost for this BART shuttle service was $\$ 5.00$ $(\$ 4.00, \$ 3.00, \$ 2.00, \$ 1.00, \$ 0.50)$ per one-way trip. How likely would you be to use this service? Would you say that you definitely would use this service, probably would use this service, might or might not use this service, probably would not use this service, or definitely would not use this service?

We followed the preferred procedure for asking questions about how much a respondent was willing to pay for a product or service by first asking about a higher payment point and lowering it subsequently, if the respondent was unwilling to pay. Questions about willingness to wait were asked in a similar way:

I'd like you to think just about waiting times for pick-ups. How likely would you be to use this BART shuttle service if the average waiting time for pick-ups was 20 minutes (15, 10, 5 minutes)? Would you say that you definitely would use this service, probably would use this service, might or might not use this service, probably would not use this service, or definitely would not use this service?

Responses to these questions help us address the fundamental issue: Given a high quality BART service in urban and suburban locations, how can ridership be improved by improving accessibility with innovative demand responsive transit systems? The statistical analyses provide a rigorous treatment of the collected data by estimating models of willingness to use, pay for, and wait for the service.

Given that the respondents' willingness to use, pay for, and wait for the shuttles are in response to hypothetical scenarios, our approach uses stated rather than revealed preferences. Such an approach is necessitated by the desire to assess demand before a new service (or product) is introduced. However, the approach has certain well-known drawbacks in terms of concerns about external validity and a host of behavioral reasons that potentially bias the responses (e.g., strategic, interviewer, and starting point biases). We recognize the potential for such biases in the data, despite our efforts to minimize them through survey design and statistical analysis. 


\section{Context}

Table 1 summarizes the demographics for the two study areas and provides characteristics of Castro Valley and Glen Park. Castro Valley is located 27 miles southeast of San Francisco, across the San Francisco Bay, and 13 miles south of Oakland. The Castro Valley study area has a population of 282,133 and a density of 4,543 people per square mile. Compared with results from the 2000 US Census (Summary File 3 ), the survey overrepresents whites and older residents. The following differences between the survey data and the census exist and are expressed as census data followed by survey data in parenthesis. The racial composition is approximately 52.8 (75.4) percent white, 10.4 (4.1) percent black, and 15.3 (11.2) percent Asian. The average age is 35.1 (49.3) years and the average household size is 2.9 (2.8) people. The road design roughly follows a grid pattern with cul-de-sacs.

\section{Table 1. Summary Statistics of Castro Valley and Glen Park}

\begin{tabular}{|c|c|c|c|c|}
\hline Study Area Characteristics & \multicolumn{2}{|c|}{ Castro Valley } & \multicolumn{2}{|c|}{ Glen Park } \\
\hline Population & \multicolumn{2}{|c|}{282,133} & \multicolumn{2}{|c|}{236,265} \\
\hline Area (sq. miles) & \multicolumn{2}{|c|}{62.1} & \multicolumn{2}{|c|}{15.9} \\
\hline Density & \multicolumn{2}{|c|}{4,543} & \multicolumn{2}{|c|}{17,744} \\
\hline Average Housing Value & \multicolumn{2}{|c|}{$\$ 298,300$} & \multirow{2}{*}{\multicolumn{2}{|c|}{$\begin{array}{c}n / a \\
\text { Grid/Cul-de-Sac }\end{array}$}} \\
\hline Road Design & & & & \\
\hline \multirow[t]{2}{*}{ Demographics } & \multicolumn{2}{|c|}{ Castro Valley } & \multicolumn{2}{|c|}{ Glen Park } \\
\hline & Survey & Census $^{1}$ & Survey & Census $^{1}$ \\
\hline White (\%) & 75.40 & 52.80 & 70.50 & 41.90 \\
\hline Black (\%) & 4.10 & 10.40 & 4.70 & 6.70 \\
\hline Asian (\%) & 11.20 & 15.30 & 12.70 & 30.70 \\
\hline Vehicles per Household (\%) & 2.50 & -- & 1.83 & -- \\
\hline Average Age & 49.30 & 35.10 & 46.70 & 36.50 \\
\hline Average Household Size & 2.80 & 2.85 & 2.53 & 3.03 \\
\hline Median family income & $\$ 67,000$ & -- & $\$ 68,000$ & -- \\
\hline Distance to station is $\leq 0.25$ miles (\%) & 20.70 & -. & 24.50 & -. \\
\hline Distance to station is between 0.25 and 0.50 miles (\%) & 6.90 & -- & 28.70 & - \\
\hline
\end{tabular}


Glen Park is located approximately three miles from downtown San Francisco, on the city's southern border. The population for the Glen Park survey area is 236,265 and has a density of 17,744 people per square mile. Whites, older residents, and smaller households are overrepresented. The racial distribution for the census (survey) was 41.9 (70.5) percent white, 6.7 (4.7) percent black, and 30.7 (12.7) percent Asian. The average age was 36.5 (46.7) years and the average household size was 3.03 (2.53).

The median distance a survey respondent lives from the nearest transit station is greater in Castro Valley than in Glen Park, as expected. The average respondent in Glen Park lives 7 to 8 blocks from the station, while in Castro Valley the median distance is 1 to 2 miles. Castro Valley respondents have 2.50 vehicles per household compared with 1.83 in Glen Park. Greater vehicle ownership is usually a result of higher incomes. However, the before tax income level in Glen Park is only slightly less than in Castro Valley. Even after controlling for household size, Castro Valley respondents still have 0.89 vehicles per person compared with 0.72 per person in Glen Park. This is likely a result of greater automobile dependency for Castro Valley respondents than for those in Glen Park. In Castro Valley, 81.0 percent of respondents travel solely by single-occupant vehicle (SOV) and only 10.8 percent by transit, whereas in Glen Park 57.3 travel solely by SOV and 37.8 percent use transit.

In addition, of those commuters who reported that they usually ride transit (including park-and-ride), a similar percentage of both urban (62.3 percent) and suburban (67.4 percent) commuters rode rail. The modes that commuters used to get to the rail station vary and reflect the demographics, density, and road design of the two neighborhoods. The majority of urban rail users ( 58.5 percent) walk or bicycle to the station, while the majority of suburban rail users (72.4 percent) access the station by SOV. Interestingly, 20.7 percent of the suburban rail users walk to the BART station.

\section{Descriptive Results}

In the survey, respondents were asked how likely they were to use the shuttle service to get to and from the rail station if the service cost what they are willing to pay and has acceptable wait, trip-length, and scheduling times. Possible outcomes were 1 (not at all willing) to 5 (very willing), with a few respondents indicating that they were unsure. The survey indicates that there is a moderate willingness to use 
shuttles in both urban and suburban neighborhoods. Approximately 20 percent of respondents reported that they were "very willing" to use a shuttle, though 35 percent of respondents were "not at all willing" to use a shuttle. It should not be interpreted that 20 percent of the respondents will permanently shift from their current mode of travel to feeder shuttles. Mode choice is a long-term decision based on the perceived utility of each mode. At most, it can be expected that these respondents will use a shuttle on a trial basis, after which time they will decide if its utility is higher than that of the alternatives.

On average, suburbanites are willing to pay more for shuttle service ( $\$ 1.67$ vs. $\$ 1.21$ ), even though they have more vehicles per person. Similarly, the average maximum time that an individual is willing to wait for a shuttle is greater in suburban communities ( 8.7 minutes vs. 7.4 minutes). This may reflect the higher cost of living for urbanites who consequently allocate less of their income to their travel budget. Additionally, this may be because suburbanites have fewer transportation options available to them and, therefore, the value they associate with additional access is greater than for urbanites. More than 40 percent of the respondents were not at all willing to pay or wait for a shuttle. Still, 10 percent were willing to pay the maximum fare level (\$5) and 20 percent were willing to wait the maximum time level (20 minutes).

It is important to quantify the percentage of respondents who are willing to use the feeder shuttle by mode and their commuter status. Respondents are categorized based on their commuter status (commuter or noncommuter), mode choice, transit choice, and BART access mode. In urban areas, 21.3 percent of all respondents indicated a high willingness to try the shuttle, compared with 20.5 percent in suburban areas. Table 2 indicates the percent of respondents by mode and commuter status that are "very willing" to use the shuttle. It shows that in urban areas, shuttles may be targeted most successfully to noncommuting SOV users (26.7 percent), noncommuting transit riders (27.6 percent), and BART users who access the station by transit ( 30.3 percent). In suburban areas, feeder shuttles could most successfully be targeted to noncommuting SOV users (22.1 percent), though this is not much greater than the area average. While this percent is lower than results in urban areas, targeting this relatively large group for the shuttle service can still have a substantial overall impact on the transportation system. Overall, these findings are logical, since those groups described above are either less affected by some of the negative aspects of shuttles (noncommuters), such as 
on-time reliability, transfers, and circuitous routing, or are accustomed to these negative aspects (BART users who access the station by transit).

It is useful to develop a profile of the groups most willing to use shuttles so that transit agencies can tailor service to meet the needs of potential customers. For example, on average, noncommuting SOV users are in their mid-60s with incomes below average. They are willing to pay, on average, slightly more than $\$ 3$ per trip and to wait about 16 minutes. Transit agencies may want to consider targeting this group for safety enhancements, such as easier boarding, and should be less concerned about their price and time sensitivity. Noncommuting transit riders in urban areas are, on average, in their late 50s with incomes significantly below average. They are willing to pay an average of $\$ 1.50$ per trip and wait almost 14.5 minutes. Price sensitivity is likely to be most important to this group. The average urbanite who accesses BART by transit are in their mid-30s, and have average incomes. Interestingly, they are willing to pay only $\$ 1.10$ per trip and to wait only 13 minutes. This group is highly price sensitive, perhaps due to a high cost of living and a greater range of transportation options available to them. They are somewhat time-sensitive, most likely because they have fixed schedules. Transit agencies may want to focus more on providing this group with timed-transfers and direct routing. However, it should be noted that sample sizes are low and findings may not be significant.

\section{Model Results}

This statistical analysis estimates models for three dependent variables: willingness to use (WTU); willingness to pay (WTP) for; and willingness to wait (WTW) for the rail feeder shuttle. Data were recorded for all respondents based on their willingness to use the shuttle, ranging from 1 (not at all likely) to 5 (very likely). However, only if the respondent was at least somewhat willing to use the BART shuttle were they asked about their willingness to pay and willingness to wait for it. This results in missing data due to sample selectivity, and can lead to bias because the sample is no longer random. If the error terms for both dependent variables are correlated, it is necessary to use a sample selection model. If the error terms are not correlated, a sample selection model is not necessary, and WTU can be estimated separately from WTP and WTW.

In sample selection models it is necessary to model WTU before WTP and WTW, because the decision to use a service is made before deciding how much one is 


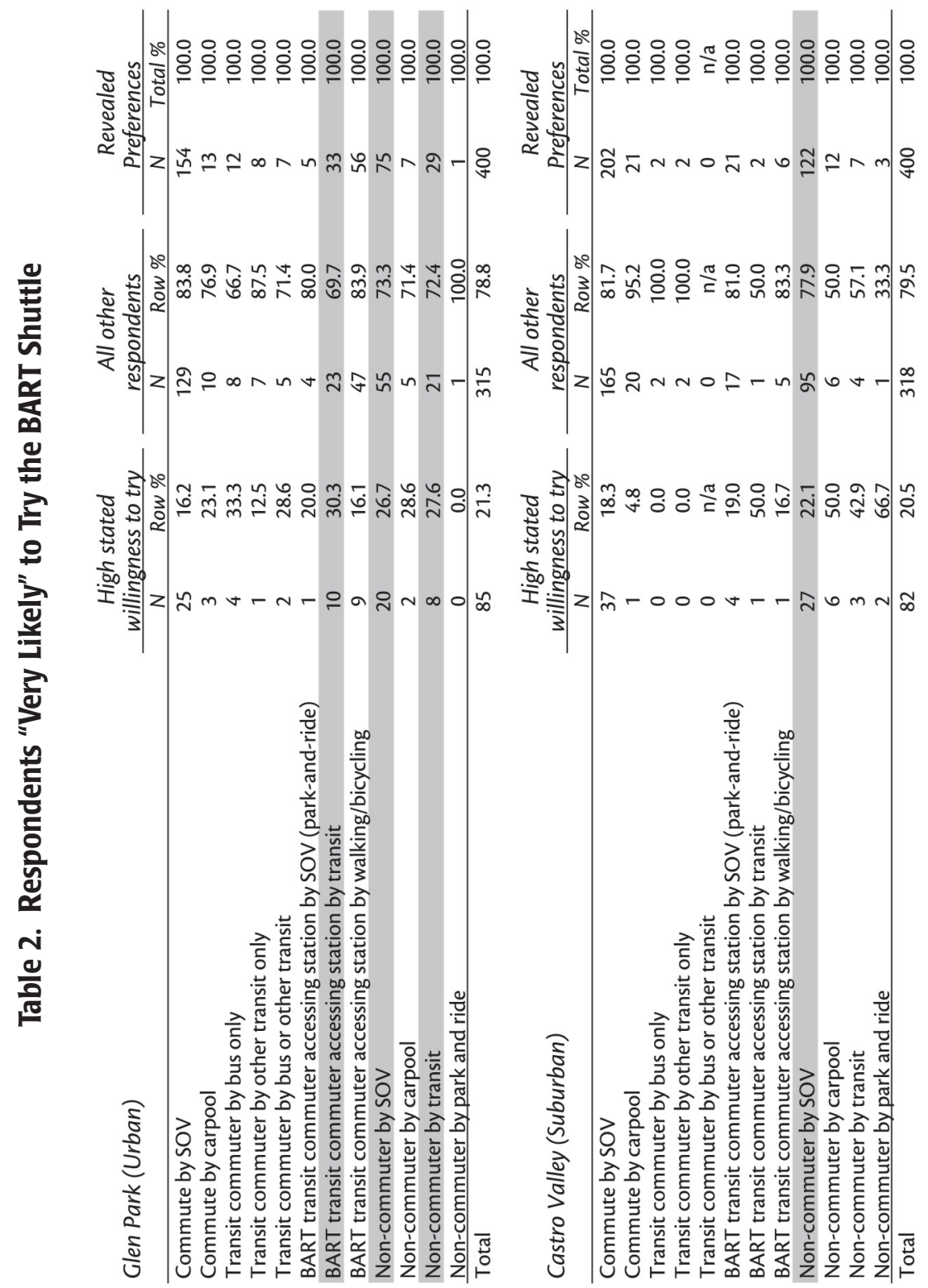


willing to pay for it and how long to wait for it. Therefore, when WTU=1, the respondent has at least some willingness to use the shuttle, while WTU $=0$ indicates that the respondent has no willingness to use the shuttle. When WTU $=0$, WTP and WTW are missing by definition.

The binary logit WTU model differentiates between respondents who are willing to use the shuttle from those who are not. WTU is coded 1 if the respondent is at least somewhat willing to use the shuttle and 0 if they are not at all willing. WTU may also help transit agencies market shuttle services to targeted groups.

OLS regression is used to estimate willingness to pay and willingness to wait, because the variables are interval data. ${ }^{2}$ The seven choices available for WTP were $\$ 0, \$ 0.50, \$ 1, \$ 2, \$ 3, \$ 4$, or $\$ 5$. The five choices available for WTW were $0,5,10,15$, or 20 minutes. Only those respondents who were willing to use the shuttle were asked about their willingness to pay and wait for it. WTP is an important variable because it can help transit agencies set fare rates. Since private vehicles will always be a more reliable transportation option than public transportation, WTW is important because it can indicate which groups have a greater threshold for delay and, therefore, are more likely to switch permanently to the shuttle.

In the Heckman selection model, we control for sample selectivity bias by estimating the probability of a positive willingness to use the shuttle in the binary equation (Equation 1), and then including it in the OLS model (Equation 2).

$$
\begin{array}{lll}
\text { Equation 1: } & \mathrm{z}=\mathrm{av}+\mathrm{u} & \text { (binary probit) } \\
\text { Equation 2: } & \mathrm{y}=\mathrm{Bx}+\epsilon & (\mathrm{OLS})
\end{array}
$$

where:

$\mathrm{z}$ is the binary (WTU) dependent variable

$a$ are the estimated parameters

$v$ are the independent variables

$y$ is the continuous (WTP) dependent variable

$\beta$ are the estimated parameters

$x$ are the independent variables

$\mathrm{u}$ and $\in$ are the relevant error terms 
In the Heckman model, the binary probit and OLS models are estimated simultaneously.

Table 3 (pages 14-15) shows the Heckman sample selection model, along with a Heckman two-step sample selection model (which is more stable when the data are problematic) and completely separate binary and OLS models. The Heckman sample selection model has more statistically significant independent variables than the other models and provides a better fit for the data. However, since Rho (which shows correlation between $u$ and $\in$ ) is -0.06 and -0.142 for the Heckman and Heckman two-step models, respectively, there is little correlation between the error terms, so the Heckman models are unnecessary. Results from the independent OLS and logit models, therefore, closely resemble those of the Heckman models.

The goodness of fit for the separate willingness to use and pay models estimated are reported and they are quite low (e.g., only $4 \%$ of the variation in willingness to pay is explained by the independent variables). In the logit willingness to use model, the odds ratios can be easily calculated by $\exp (\mathrm{a} \times)$.

Several variables in this analysis are notable. In line with our expectations, people who live within $1 / 2$ mile of a rail station are also less willing to use the shuttle $(p<0.01)$, since they are within walking distance of the station. However, while living in the urban neighborhood is negatively associated with WTU, this relationship is not statistically significant. The socioeconomic variables show that females $(p<0.05)$, younger people, and elderly people are more willing to use the shuttle $(p<0.01)$. In terms of current mode choice, noncommuting SOV users $(p<0.10)$ and BART users accessing the station by transit $(p<0.01)$ are more willing to use the shuttle than commuting SOV users, though transit users commuting by modes other than rail and bus (likely by ferry) are less willing $(p<0.10)$.

For the WTP model, urbanites are less willing to pay for the shuttle than suburbanites $(p<0.01)$. While this is in agreement with our hypothesis, one of the explanations we posited was that urban residents would be willing to pay less due to a higher cost of living. This variable was tested in an earlier model and was found to be insignificant. However, it still may be that urban residents are more price-sensitive because they have a wider range of transportation options available to them. Few of the race variables are significant, except that Latinos are willing to pay more for the shuttle than Caucasians. This is in agreement with our expectation that minorities are willing to pay more for the shuttle due to their transit predisposition. However, the other race variables are insignificant. BART users accessing the 


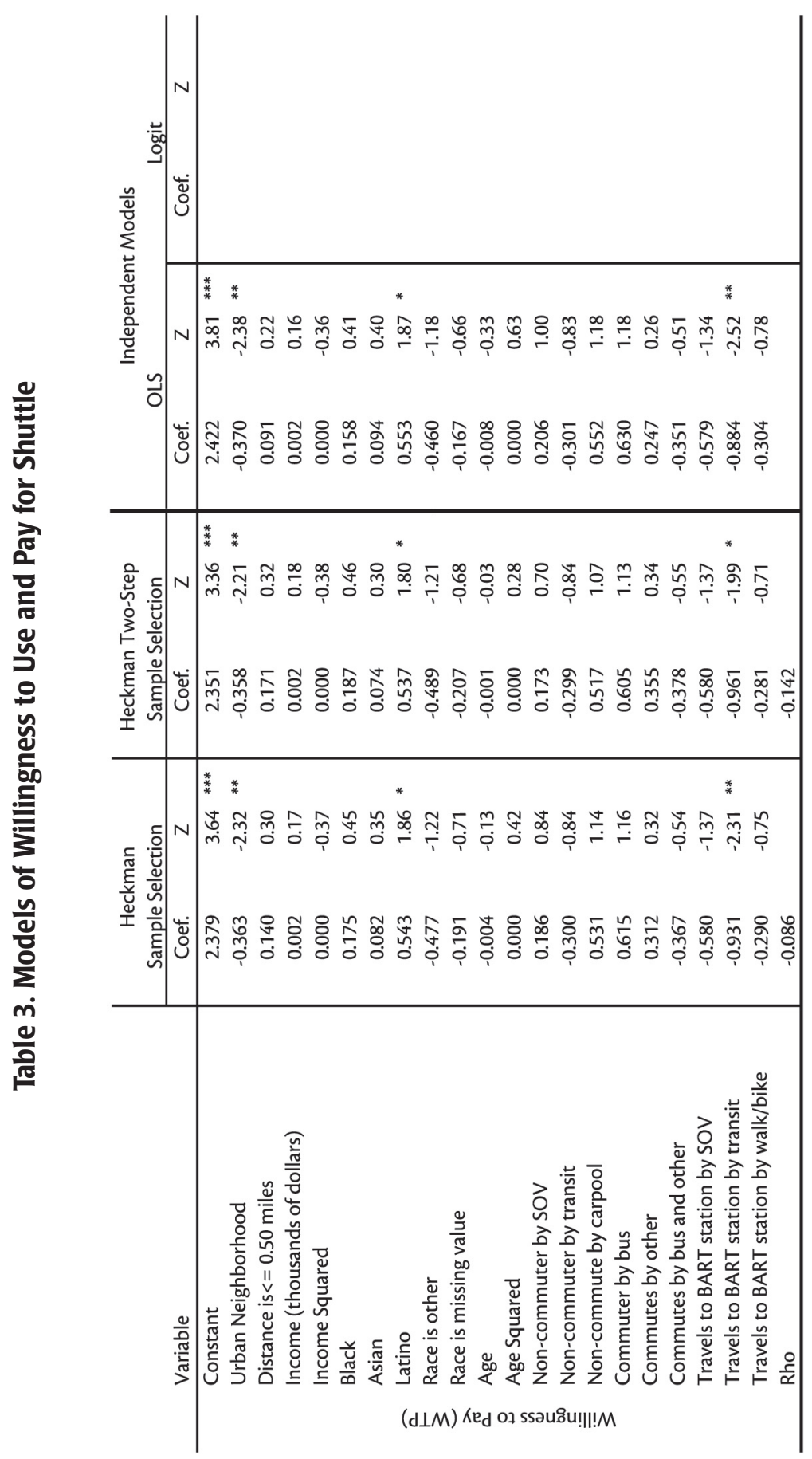




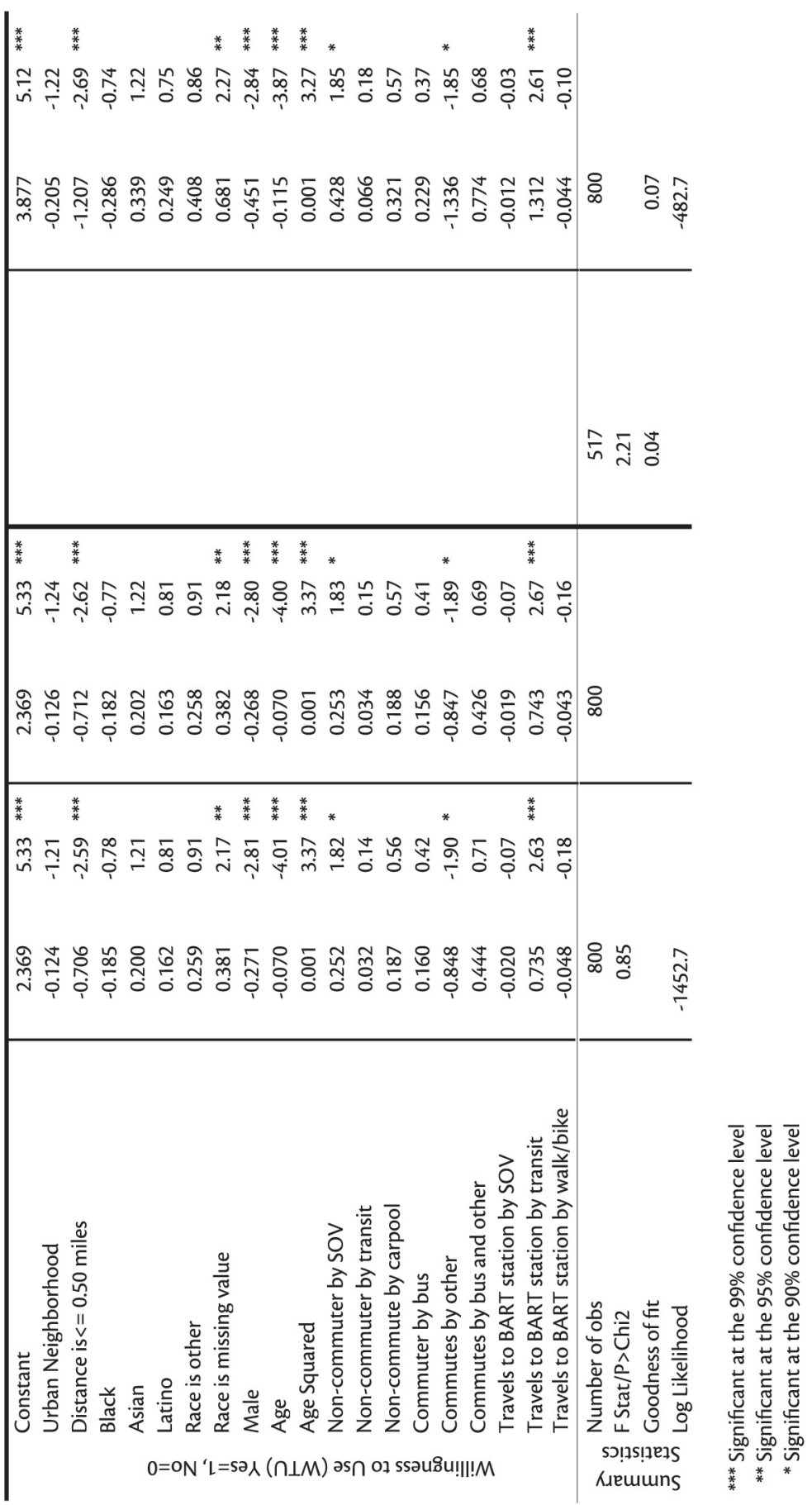




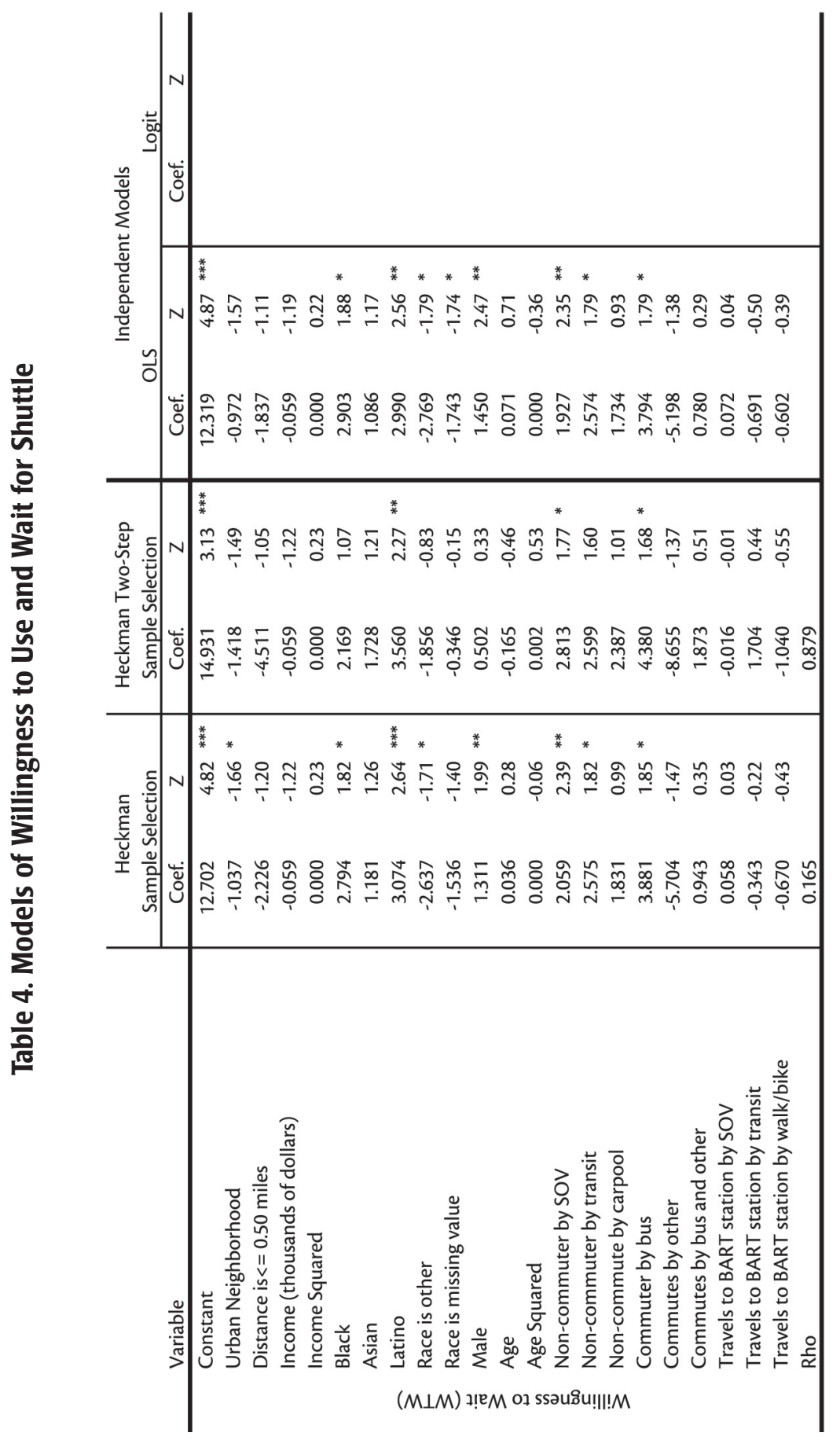




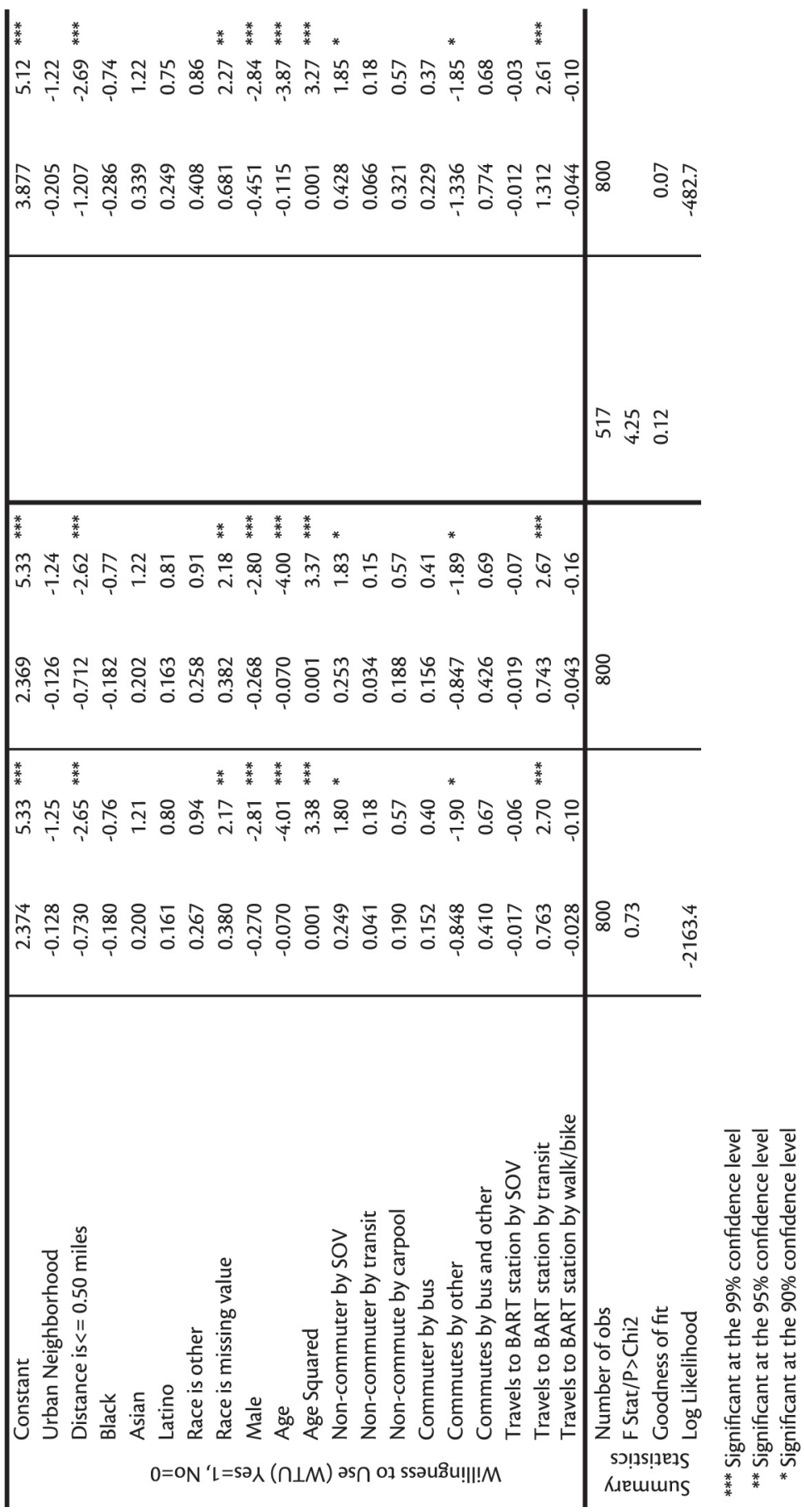


station by transit are less willing to pay for the feeder shuttle than commuting SOV users $(p<0.05)$.

Table 4 shows models for WTU and WTW. Results for WTU are nearly identical to those found in Table 3, as expected. For WTW, the Heckman sample selection model again has a low correlation between error terms $(\mathrm{Rho}=0.165)$ and is, therefore, not necessary. The results from the OLS model are similar to those of the Heckman model. Both Blacks $(p<0.10)$ and Latinos $(p<0.05)$ are willing to wait longer for the shuttle than Caucasians. This is likely due to their transit disposition. In addition, females are willing to wait about 1.5 minutes less than males $(p<0.10)$, likely due to safety concerns. In terms of current mode choice, noncommuting SOV users $(p<0.05)$, noncommuting transit users $(p<0.10)$, and bus commuters $(p<0.10)$ are willing to wait longer for the shuttle, by approximately $2,2 \frac{1}{2}$, and 4 minutes, respectively.

While travel time to the nearest transit station is an important measure of impedance, it was not included in the final model due to missing data in the variable and statistical insignificance in previous models.

\section{Conclusions}

The purpose of this research was to investigate whether transit agencies can use rail feeder shuttles to expand their service to underserved areas and those groups who will use the service. Using a behavioral survey in two San Francisco neighborhoods, this study attempted to answer this question in two ways. First, it sought to profile those groups who are most likely to switch to the proposed shuttle service. The study shows that there is significant interest in using rail feeder shuttles, as long as they have acceptable fares, wait times, trip lengths, and scheduling times. As is to be expected, there is no one-size-fits-all approach to offering feeder shuttle service. Rather, service must be tailored to individual groups to meet their needs. This survey found that three mode choice groups, in particular, show promise as target groups: noncommuting SOV users, noncommuting transit users in urban areas, and rail users who access stations by transit in urban areas. In terms of socioeconomics, women, younger, and elderly people also show promise. The challenge for transit agencies is to provide passengers with the level of service that they require. By funding advanced technologies, transit agencies can improve level of service for passengers while reducing costs to service providers by improving scheduling, routing, transfers, and passenger information. 
Second, the research rigorously analyzed the factors that influence willingness to use, pay, and wait for rail feeder shuttles. Higher willingness to use the shuttle was associated with living beyond the $1 / 2$-mile walking distance of the nearest transit station, women, younger, and elderly respondents, noncommuters who travel by SOV, and BART users who access rail stations by transit. Higher willingness to pay for the shuttle was associated with suburbanites and Latinos, although BART users accessing the station by transit are less willing to pay for the shuttle. Higher willingness to wait for a shuttle was associated with Blacks, Latinos, males, as well as noncommuting SOV users, noncommuting transit riders, and bus commuters. Overall, the study finds that a consumer-based shuttle service might be feasible, especially if targeted at those groups most willing to use the shuttle. Transit agencies may be able to more accurately price the shuttle service fare and develop scheduling policies based on the results of this study. Policymakers can consider rail feeder shuttles as a valuable alternative in bringing demand from lower density areas to increase the accessibility of line-haul services.

There are certain limitations. First, the CATI survey was intended to satisfy sample requirements for gender and age (above 18). However, as we point out in discussing the context, the survey responses show overrepresentation of certain groups (whites and older residents) compared with the 2000 census data. This might limit the generalization of the findings. Second, compared to other cities, San Francisco is somewhat unique in terms of population, openness to innovations, and geography. Issues investigated in this study are context-specific and may not generalize to other cities. Still, this study clearly suggests that public transportation planners in other (similar) large metropolitan areas should explore and evaluate expanding transit service to underserved urban and suburban areas via shuttles.

Shuttle trips would be part of a linked trip (shuttle and line-haul). Therefore, shuttle choice should be nested within a larger choice set. This would require people to weigh door-to-door travel times, not just time (or distance) for the shuttle link. Future research on shuttles should investigate them as part of a linked trip.

\section{Endnotes}

${ }^{1}$ Minors are also potential transit shuttle passengers, however they are excluded due to privacy concerns.

${ }^{2}$ Since the data are categorical, rather than interval, there is potential for violation of OLS assumptions. 


\section{References}

Cervero, Robert. 1995. Rail access modes and catchment areas for the BART system. BART@20. University of California at Berkeley, Institute of Urban and Regional Development.

Cervero, Robert. 1994. Transit-based housing in California: Evidence on ridership impacts. Transport Policy 1 (3):174-183.

Khattak, A. J., and M. Hickman. 1998. Automatic Vehicle Location and ComputerAided Dispatch Systems: Design and application considerations. Journal of Public Transportation 2 (1): 1-28.

Khattak, A. J., H. Noeimi, H. M. Al-Deek. 1996. Taxonomy for Advanced Public Transportation Systems. Journal of Public Transportation 1 (1): 43-68.

Ghani, Gisela, and Robert B. Dial. 2004. ADART Order Entry System. TRB 2004 Annual Meeting, Nation Research Council. Washington DC.

Hickman, M., and M. Blume. 2001. An investigation of integrated transit service. Southwest Region University Transportation Center, College Station, TX.

\section{About the Authors}

DAVID ANSPACHER (danspacher@bmisg.com) received his Masters of Regional Planning from the University of North Carolina at Chapel Hill. He works with BMISG, Inc., a transportation engineering and planning firm located in Silver Spring, Maryland, and Vienna, Virginia.

ASAD J. KHATTAK (khattak@email.unc.edu) is associate professor in the department of regional planning and directs the Carolina Transportation Program. He received his master's and Ph.D. degrees in civil engineering from Northwestern University. He has worked at the University of Oxford in England and at the Institute of Transportation Studies at the University of California, Berkeley. Dr. Khattak is the editor of the Journal of Intelligent Transportation Systems.

YouNGBIN YIM (ybyim@uclink.berkeley.edu) is associate research engineer in the PATH program at the University of California, Berkeley. She received her Ph.D. in civil engineering from the University of California, Berkeley. Her research interests include traveler behavior and intelligent transportation systems.Using GPS Technology to Measure On-Time Running of Scheduled Bus Services 